\title{
Classification of Extreme Rainfall for a Mediterranean Region by Means of Atmospheric Circulation Patterns and Reanalysis Data
}

\author{
Giuseppe Cipolla ${ }^{1} \cdot$ Antonio Francipane ${ }^{1} \cdot$ Leonardo Valerio Noto $^{1}$ (D)
}

Received: 7 February 2020 / Accepted: 30 June 2020/

Published online: 8 July 2020

(C) The Author(s) 2020

\begin{abstract}
The atmospheric circulation can be recognized as one of the causes of severe rainfall events occurrence. Such events, especially when are characterized by short durations and high intensities, result in flood events in the Mediterranean area. It is very important to understand how these heavy rainfall events, which can be usually identified with convective rainfall, are related to the different types of atmospheric circulation. In order to do this, some weather circulation patterns (WPs), which have been derived for the Europe, have been first connected with the rainfall annual maxima (AMAX) recorded over the Sicily. The analyses allowed to identify those WPs that are more likely to result into the occurrence of the AMAX. Secondly, two ERA-Interim reanalysis indexes have been used to define a criterion to distinguish those AMAX mainly due to a convective component from those more related to a stratiform precipitation, also detecting a transient zone between these two types of events. Finally, the main results have been connected together with the aim to define a set of triggering factors of extreme rainfall events.
\end{abstract}

Keywords Weather circulation patterns $\cdot$ Rainfall AMAX $\cdot$ Convective precipitation $\cdot$ Stratiform precipitation $\cdot$ Mediterranean $\cdot$ Sicily

\section{Introduction}

Since the impacts of climate change on the environment have been constantly rising over the last decades, scientists have paid much attention to understand the effects of this phenomenon

Electronic supplementary material The online version of this article (https://doi.org/10.1007/s11269-02002609-1) contains supplementary material, which is available to authorized users.

Giuseppe Cipolla

giuseppe.cipolla04@unipa.it

1 Department of Engineering, University of Palermo, Palermo, Italy 
(Kunkel et al. 1999). Climate change leads to different kinds of extremes (Hegerl et al. 2014), such as heavy rainfall events and droughts, which may cause several damages such as loss of human lives and economic damages. Dai (2011) presented a review of the recent scientific literature about drought, affirming that global warming has contributed to the enhancement of the atmospheric water demand and to the increase of the expected arid areas for the twenty-first century in several continents. Aronica et al. (2002) and Arnone et al. (2013) studied the changes in rainfall statistics over Sicily (Italy) finding out an increasing trend in the occurrence of shortest-duration rainfall events. Furthermore, many other studies demonstrated that extremes are tending to increase their frequency of occurrence and intensity (Collins et al. 2013; Field et al. 2012). In order to determine the response of precipitation extremes to global warming, the INTElligent use of climate models for adaptioN to non-Stationary hydrological Extremes (INTENSE) project aimed to figure out the relationship between large-scale warming, atmospheric circulation, and short-duration extreme rainfall events (Blenkinsop et al. 2018). To achieve this goal, the INTENSE project based on a huge database of subdaily rainfall observations at the global scale. The dataset, along with advanced climate models, has been employed to better understand which are the drivers of extreme rainfall events and look at the influence of large-scale atmospheric circulation and local thermodynamics on the extremes.

With regard to the broad-scale atmospheric circulation, Neal et al. (2016) presented some weather circulation patterns (WPs) derived by the UK-Met Office. Each WP was representative of a specific type of atmospheric circulation over Europe for each day ranging between 1850 and 2016. Starting from the daily Mean Sea Level Pressure (MSLP) data of the European and North Atlantic Daily to Multidecadal Climate Variability (EMULATE) database, Fereday et al. (2017) analyzed how the atmospheric circulation influences the trends in regional precipitation by applying a cluster analysis to the data. This analysis highlighted that the circulation variability is one of the drivers of a great part of the changes in European precipitation. Richardson et al. (2018) connected the WPs with daily precipitation and with some indexes related to drought, such as the Standardized Precipitation Index (SPI) and the Drought Severity Index (DSI), for the UK, distinguishing between WPs linked to precipitation and WPs connected with drought.

When heavy rainfall events present high intensity and short duration they can be often associated with convective events. Due to their characteristics, especially when they hit small catchments with low times of concentration, they can result in flash floods (Forestieri et al. 2016; Noto and La Loggia 2009) and cause economic damages and, more relevantly, human lives losses. The occurrence of these kinds of phenomena in many areas of Europe over the last few years, has contributed to raising the importance of understanding which factors could be recognized as drivers of these events. Gabriele and Chiaravalloti (2013) set up a method to distinguish between convective and stratiform rainfall events, by using two different reanalysis indexes, the Convective Available Potential Energy (CAPE) and the divergence of moisture flux, named $Q$ vector Divergence (QD). In their work, the authors performed a regionalization on the base of the daily rainfall data recorded by several gauges located throughout Italy. By defining a joined condition with the CAPE and QD, they were able to distinguish between regions characterized by the occurrence of convective rainfall and regions mainly affected by stratiform rainfall events. By associating some indexes with these rainfall events, the authors found that high values of CAPE correspond to strong convective events that they called tornado-like events. Iturrioz et al. (2007) computed the QD from the geopotential height and temperature and analyzed some recorded precipitation data for some gauges across Spain, 
finding out that the dynamic instability, and thus the occurrence of stratiform rainfall events, is connected with negative values of QD.

Despite advances made in recent years, the distinction between convective and stratiform precipitation is not trivial and still today a challenge (Llasat et al. 2005), since it is connected with the characteristics of rainfall events, such as the rain rate and duration, which are usually different for a convective and a stratiform precipitation (Gaál et al. 2014). While some studies tried to establish a criterion to make a net distinction between convective and stratiform rainfall events (Gabriele and Chiaravalloti 2013; Lang et al. 2003; Tremblay 2005), some others affirm that a so clear-cut separation in only two classes is improper (Houze 1997; Kyselý et al. 2016). With this regard, Houze (1997) affirmed that, in some cases, convective phenomena are embedded in the same stratiform regions. This happens in the older convection regions, where the humid air moves slower upwards than in the younger convective regions. In this case, the radar echoes are similar to those of a stratiform precipitation, even though they also present a convective component. In this respect, Rulfova and Kyselý (2013) introduced a class of mixed $\backslash$ unresolved events to take into account all those events that, according to their algorithm, could be classified as both convective and stratiform events or do not have a sufficiently clear distinction between those two classes.

In this work, extreme precipitation events for the Sicily (Italy) have been connected with some UK centered WPs to answer the following research questions: can the atmospheric circulation be recognized as a driver of severe rainfall events? Since even the Sicily has been experimenting heavy rainfall events and consequent flash floods in the last years, is it possible to define some specific schemes of UK centered WPs that are responsible for leading to the occurrence of AMAX in Sicily? Is it possible to identify an AMAX seasonality and relate it with some WPs? Finally, is it possible to involve some reanalysis data, such as the CAPE and the Vertical Integral of Divergence of Moisture Flux (VIDMF) in the assessment of convective and stratiform AMAX?

In order to answer these questions, WPs have been used as precursors of heavy rainfall events (i.e., AMAX). A novel criterion, based on a fuzzy approach, valid for different geographical areas of Sicily, is here presented to distinguish convective from stratiform and mixedlunresolved rainfall AMAX and connect them to their seasonality. This criterion could be, if well calibrated, extended to other regions of the globe and used as a tool to predict potentially heavy rainfall events.

\section{Material}

\subsection{Study Area}

Sicily (Italy) is the largest island of the Mediterranean Sea and covers an area of about $25,000 \mathrm{~km}^{2}$. The elevation ranges from $0 \mathrm{~m}$ a.s.l. along the coast to more than $3000 \mathrm{~m}$ a.s.l. at the volcano Etna.

Precipitation has a high spatial and temporal variability. Mean annual precipitation (MAP) ranges between about $360 \mathrm{~mm}$ in the southeastern part of the island and about $1900 \mathrm{~mm}$ in the northeast of the region (Caracciolo et al. 2018; Di Piazza et al. 2011) with an overall mean of about $700 \mathrm{~mm}$. With reference to the temporal variability, instead, rainfall is mostly concentrated in winter, whilst the summer season (i.e., June, July, and August) is usually rainless. 


\subsection{Precipitation Dataset}

An extensive database of rainfall Annual MAXima (AMAX) for the entire Sicily and the duration of 1, 3, 6, 12, and $24 \mathrm{~h}$ has been provided by the Autorità di Bacino - Regione Siciliana. For each rain gauge of the network, the database consists in a time series of AMAX and the corresponding day of the occurrence. The database has 394 gauges dislocated throughout the Sicily and provides data between 1928 and 2016. In order to ensure a reasonable statistical analysis at the rain gauge level, 114 rain gauges with less than ten years of AMAX have been discarded from the original database. Figure 1 shows the spatial distribution of the rain gauge network over Sicily with the circles size providing an indication of the number of available AMAX for each rain gauge. Most of the rain gauges considered provides a number of rainfall AMAX varying between 20 and 60 years.

\subsection{Weather Circulation Patterns (WPs) Dataset}

The database of the weather circulation patterns (WPs) was developed by the UK-Met Office and presented by Neal et al. (2016). In particular, for all the days in between 1850 and 2016, WPs represent the type of atmospheric circulation that occurred on that specific day over a European domain centered in the UK. In Neal et al. (2016), a set of 30 WPs was initially derived and thereafter aggregated in a database containing only 8 WPs on the base of the spatial correlation among WPs centroids, thus considering the similarity of the WPs. Hereafter, the WPs belonging to the simplified ensemble will be denoted as $\mathrm{WP}_{8, \mathrm{x}}$, while the original one will be indicated as $\mathrm{WP}_{30, \mathrm{y}}$, where $x$ and $y$ range between 1 and 8 and between 1 and 30, respectively. With reference to the only $\mathrm{WP}_{8,1}$ and $\mathrm{WP}_{8,2}$, which have the

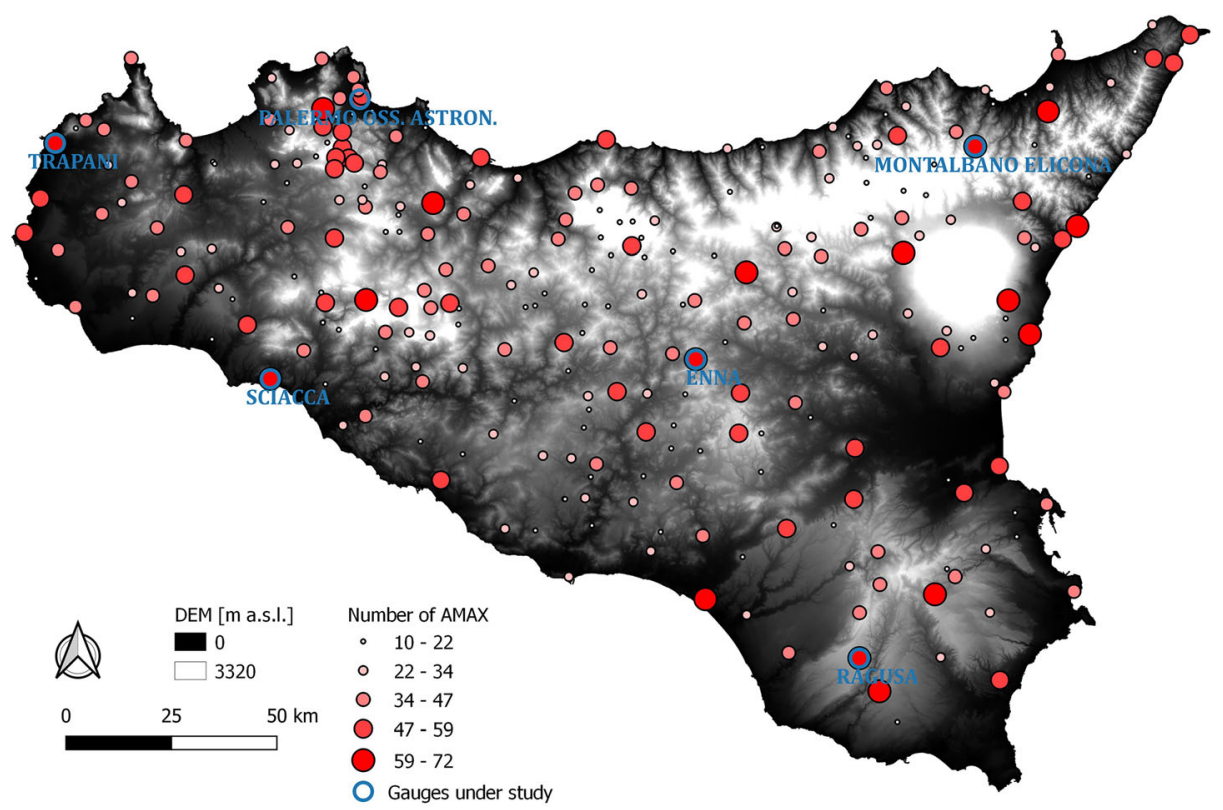

Fig. 1 Spatial distribution of rain gauges and sample size (i.e., number of AMAX) for each rain gauge overlaid on the Digital Elevation Model (DEM) of Sicily. The six rain gauges used to perform a classification of rainfall AMAX are highlighted with a blue circle 
highest frequencies of occurrence, it is possible to notice that $\mathrm{WP}_{8,1}$ presents positive Mean Sea Level Pressure (MSLP) anomalies in the northern part of Europe and negative MSLP anomalies in the Southern Europe, where Sicily is located, whilst $\mathrm{WP}_{8,2}$ shows the opposite spatial pattern even though lower values of MSLP. For more details on WPs and an extensive description of the MSLP anomalies under the other WPs the reader is referred to Neal et al. (2016).

\subsection{Reanalysis Dataset}

The reanalyzed meteorological database of the ERA-Interim Archive has been here used to extract the spatially distributed time series of CAPE and VIDMF for Sicily. The CAPE is defined as the amount of the buoyant energy that is available for a particle to speed up its upward movement (Gabriele and Chiaravalloti 2013; Moncrieff and Green 1972; Moncrieff and Miller 1976). It is calculated as:

$$
C A P E=g \int_{L F C}^{E L} \frac{T_{p}-T_{e}}{T_{e}} d z
$$

where $g$ is the gravitational acceleration, $L F C$ and $E L$ are the levels of free convection and equilibrium, respectively, $T_{p}$ and $T_{e}$ are the virtual temperatures of the lifting parcel and of the environment, respectively. High values of CAPE may cause strong thermodynamic instability and are usually related to convective rainfall events.

The VIDMF is the Vertical Integral (VI) of the Divergence of Moisture Flux (DMF). In many studies, such as Rasmusson (1971), Mariotti et al. (2002), Gabriele and Chiaravalloti (2013), DMF is presented as a very powerful index to describe frontal rainfall events associated with stratiform precipitation. Since the divergence of moisture flux data were not available in the ERA-Interim Archive, the VIDMF was used as a proxy of the DMF to detect the stratiform precipitation. The VIDMF can be expressed as:

$$
V I D M F=\nabla \frac{1}{g} \int_{0}^{l} v q\left(\frac{\partial p}{\partial \eta}\right) d \eta
$$

In Eq. (2) the term $v$ is the wind velocity, $q$ is the atmospheric specific humidity, and $p$ is the atmospheric pressure. The integral is performed from the surface (level 0 ) to the top of the atmosphere (level $l$ ) with respect to the vertical coordinate $(\eta)$.

The database, which is provided by the European Centre for Medium-Range Weather Forecast (ECMWF, https://www.ecmwf.int/), provides the reanalysis data at the global scale from 1979 up to day as analysis and forecast data. The analysis data come from observations and are used to produce a realistic state estimate of the atmosphere; they are updated every six hours (00:00, 06:00, 12:00, and 18:00 UTC). Forecasts, instead, which mostly rely on models, project the atmospheric state to the future and are used to provide valuable background information to the system for the next analysis cycle. In particular, forecast surface parameters, such as CAPE, are available at four time steps (3, 6, 9, and $12 \mathrm{~h})$ from 00 and 12 UTC, while the VIDMF, which is an analysis parameter, is available only at 00:00, 06:00, 12:00, and 18:00 UTC each day.

The daily spatial distributions of CAPE and VIDMF, at the spatial resolution of $0.125^{\circ} \times$ $0.125^{\circ}$ and for the period 1979-2016, have been retrieved for an area covering all the Sicily. 


\section{Methodology and Results}

\subsection{Frequencies of Occurrence of AMAX under Different WPs}

In order to better understand how the WPs may influence the occurrence of AMAX, the pooled AMAX from all the gauges, for each of the available durations, have been first associated with one of the $\mathrm{WP}_{8, \mathrm{x}}$, on the base of the day of occurrence. This allowed to calculate the frequency of occurrence of AMAX for each duration and each $\mathrm{WP}_{8, \mathrm{x}}$ (Fig. 2a). The same procedure has been applied to the subset of AMAX higher than the median value $R$-Med (Fig. 2b). Figure 2c shows the differences between the two previous results.

In both cases, Fig. 2a and $\mathrm{b}$ highlight the noticeable contribution of $\mathrm{WP}_{8,1}$ to the occurrence of AMAX for all the durations. Figure $2 b$ shows an increasing pattern of the frequency of occurrence with the duration for the $\mathrm{WP}_{8,2}$ that in Fig. 2a stops with the duration of $12 \mathrm{~h}$. However, even if in $\mathrm{WP}_{8,3}$ and $\mathrm{WP}_{8,6}$ it is possible to observe an increasing pattern of the differences with the duration, the negligible differences shown in Fig. 2c (between about $\mp 1 \%$ ) lead to conclude that the two samples of AMAX are characterized by the same behavior under all the $\mathrm{WP}_{8, \mathrm{x}}$.

The results of the analysis extended to the $\mathrm{WP}_{30, \mathrm{y}}$, which are reported in Section $\mathrm{S} .1$ of the supplementary material, reveal that many $\mathrm{WP}_{30, \mathrm{y}}$ contribute to the occurrence of AMAX with an almost constant contribution. This is most likely due to the small extension of the region,
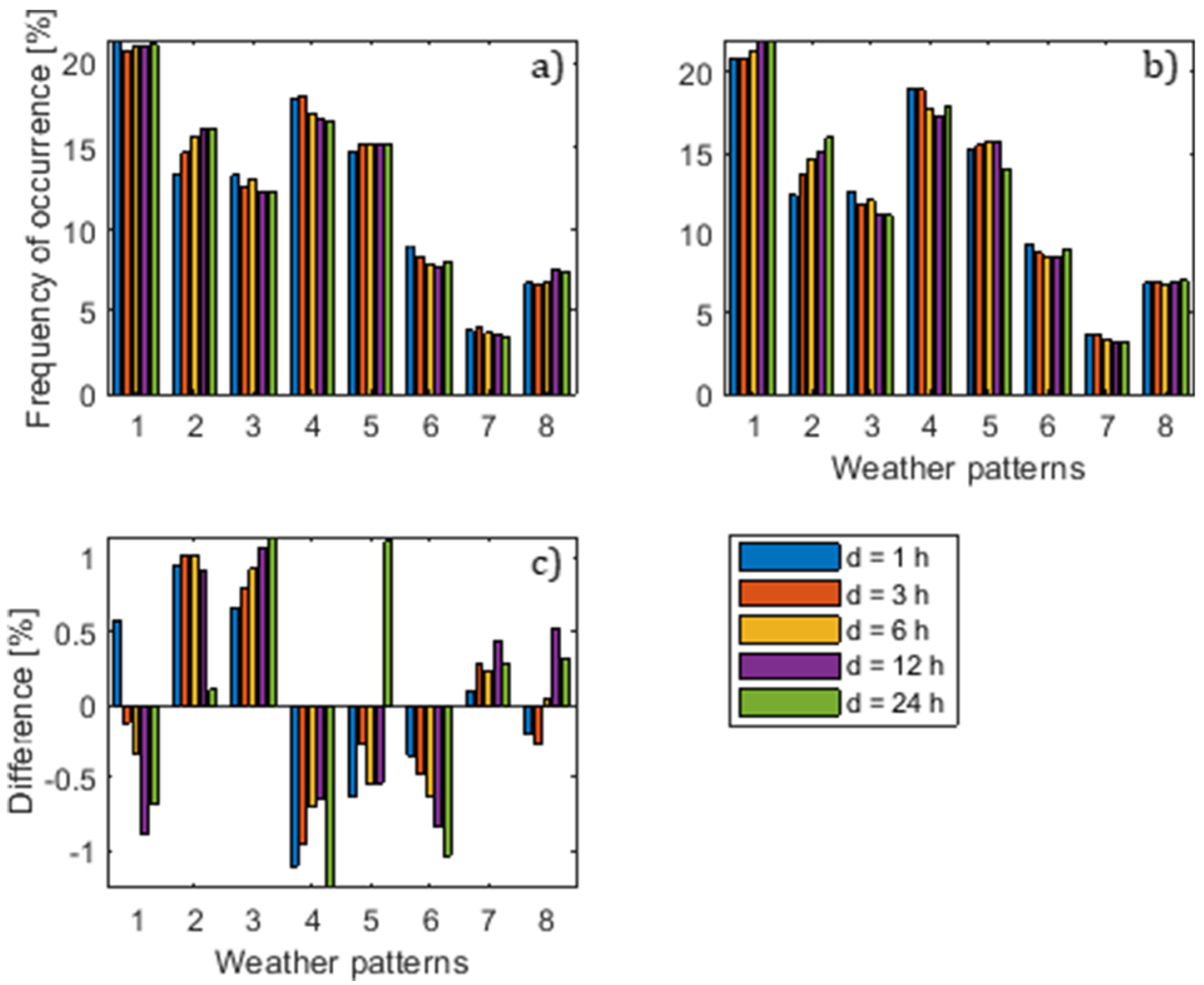

Fig. $2 \mathrm{WP}_{8, \mathrm{x}}$ frequency histograms for (a) all the pooled AMAX, (b) the AMAX greater than R-Med and $\mathbf{c}$ the differences between the frequencies of occurrence shown in (a) and (b) 
which involves a small variability in terms of atmospheric circulation that leads to the AMAX occurrence. For this reason, the subsequent analyses have been performed considering only the $\mathrm{WP}_{8, \mathrm{x}} \cdot$

\subsection{Frequencies of Occurrence of Extreme AMAX under Different WPs}

In order to investigate the behavior of the most severe AMAX under the $\mathrm{WP}_{8, \mathrm{x}}$, the occurrence frequencies of all the AMAX higher than the 75th, 90th, and 99th percentiles have been calculated (Fig. 3). With particular attention to the 99th percentile (Fig. 3c), which represents the most extreme events, the analysis highlights that, for the $\mathrm{WP}_{8,1}$, the occurrence frequencies increase considerably as compared to the other $\mathrm{WP}_{8, \mathrm{x}}$. A similar behavior is recognizable for the 24-h AMAX under $\mathrm{WP}_{8,4}$.

In any case, to be fair, it is not easy to detect a pattern of the occurrence frequency with the duration, under each WP, with such an analysis because of the small dataset resulting from AMAX greater than the 99th percentile (about twenty values per duration). In the same manner, the small dimension of the dataset also affects the results of all the analyses conducted with reference to the other percentiles.
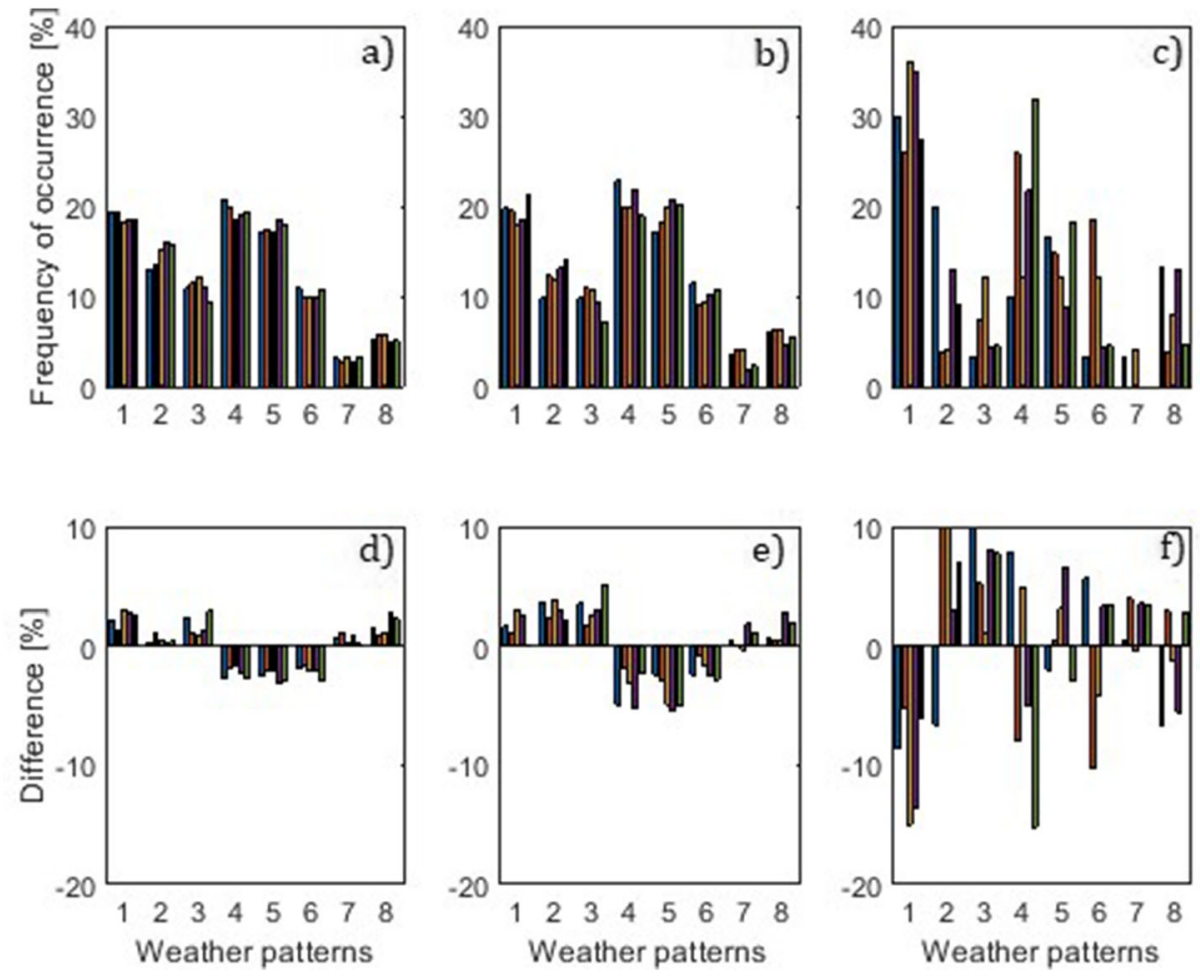

Fig. 3 Frequency histogram under the $\mathrm{WP}_{8, \mathrm{x}}$ related to all the AMAX higher than (a) 75th percentile, (b) 95th percentile and (c) 99th percentile. The differences between the frequency of occurrence of pooled AMAX (Fig. 2a) and the frequency of occurrence of the AMAX greater than their (d) 75th, (e) 95th and (f) 99th percentile are also displayed. The legend is the same as that in Fig. 2 


\subsection{Conditional Probability of AMAX for Given WPs}

In order to define the probability of occurrence of an AMAX for a given duration, once a specific WP occurs, the Bayes' theorem has been used. In general, the Bayesian approach defines the cause-effect relationship between two variables. In this case, it has been used to assess the probability that, for a given duration, a certain $\mathrm{WP}_{8, \mathrm{x}}$ causes an AMAX.

$$
P\left(\mathrm{WP}_{8, \mathrm{x}} \mid \text { AMAX }\right)=\frac{P\left(\mathrm{AMAX} \mid \mathrm{WP}_{8, \mathrm{x}}\right) \cdot P\left(\mathrm{WP}_{8, \mathrm{x}}\right)}{\sum_{x=1}^{8} P\left(\operatorname{AMAX} \mid \mathrm{WP}_{8, \mathrm{x}}\right) \cdot P\left(\mathrm{WP}_{8, \mathrm{x}}\right)}
$$

The Eq. (3) provides the factor $P\left(\mathrm{WP}_{8, \mathrm{x}} \mid \mathrm{AMAX}\right)$, which stands for the probability that a certain $\mathrm{WP}_{8, \mathrm{x}}$ has resulted in a given AMAX. The factor $P\left(\mathrm{AMAX} \mid \mathrm{WP}_{8, \mathrm{x}}\right)$ is the probability of an AMAX, better known as the likelihood, given the occurrence of a certain $\mathrm{WP}_{8, \mathrm{x}}$. This term is different from the output of Eq. (3); in fact, for the assessment of $P\left(\mathrm{WP}_{8, \mathrm{x}} \mid\right.$ AMAX) we took into consideration the frequency of occurrence of all the $\mathrm{WP}_{8, \mathrm{x}}$ that could result in the AMAX considered, namely $P\left(\mathrm{WP}_{8, \mathrm{x}}\right)$, while the factor $P\left(\mathrm{AMAX} \mid \mathrm{WP}_{8, \mathrm{x}}\right)$ can be assessed as the frequency of occurrence of a certain-duration AMAX under a single $\mathrm{WP}_{8, \mathrm{x}}$.

Equation (3) was applied to the ensemble of the pooled AMAX of all the rain gauges for a fixed duration. Results, which are shown in Section S.2 of the supplementary material, reveal that AMAX, for any duration, are mostly caused by the occurrence of $\mathrm{WP}_{8,1}$ (with an almost constant frequency value at all the durations considered), $\mathrm{WP}_{8,2}$ (especially at the longest duration), and $\mathrm{WP}_{8,4}$. In particular, the $\mathrm{WP}_{8,2}$ is the only one to show a significant increasing pattern of the conditional probability with the duration.

\subsection{Seasonality in the Occurrence of AMAX}

With the purpose to investigate the presence of a seasonality in the occurrence of AMAX, the previous analyses have been reiterated for two datasets including the AMAX occurred between May and October (namely the summer period) and between November and April (namely the winter period). A first analysis highlighted that the percentage of AMAX occurred during the summer period decreases as the duration increases, whereas the winter period has the opposite behavior (Fig. 4). With reference to Fig. 4, the hourly AMAX occur in about $65 \%$ of the cases during the summer period and the $35 \%$ in the winter period. Regarding the 24-h AMAX rainfall, instead, the $60 \%$ of them occurs in the winter period and the $40 \%$ during the summer period. This result, despite the simplicity of the analysis, shows that the greatest part of the rainfall events occurring during the summer period are characterized by short durations and high intensities, whilst the winter period presents longer duration precipitation events with low intensities. Many studies recognize in these elements the typical characteristics of the convective (Gaál et al. 2014; Gabriele and Chiaravalloti 2013; Llasat et al. 2005) and stratiform (Gaál et al. 2014; Gabriele and Chiaravalloti 2013; Llasat et al. 2005) precipitation, respectively.

In order to replicate the analyses made on the entire dataset, the frequency histograms for the $\mathrm{WP}_{8, \mathrm{x}}$ occurred in the summer (Fig. 5a) and winter (Fig. 5b) and their differences (Fig. 5c) have been first set up. Each AMAX has been then linked to the corresponding $\mathrm{WP}_{8, \mathrm{x}}$, for the assessment of the frequency histograms of the AMAX under each $\mathrm{WP}_{8, \mathrm{x}}$ (Fig. $5 \mathrm{~d}$ and e refer to summer and winter period, respectively) and their differences (Fig. 5f). Finally, through the 


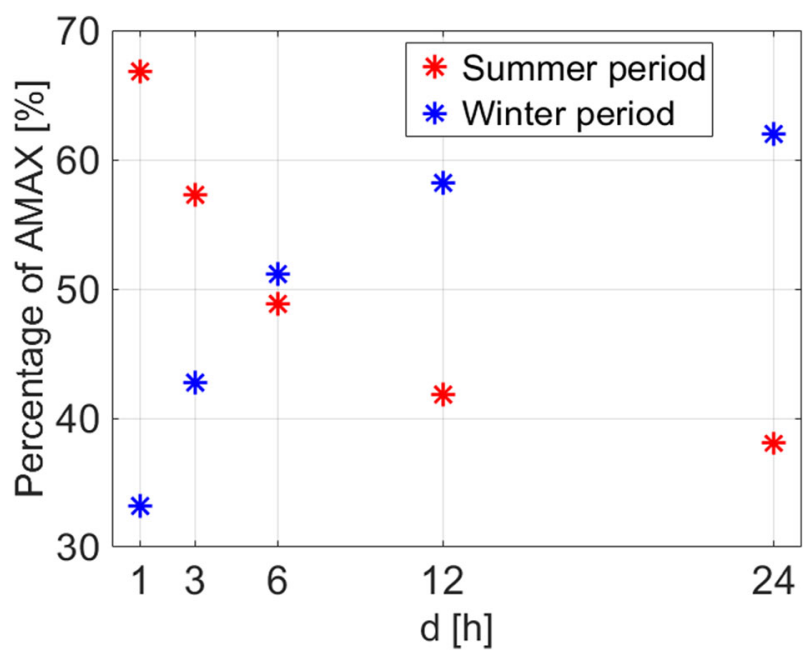

Fig. 4 Percentage of the pooled rainfall AMAX occurred during the summer (red asterisks) and winter period (blue asterisks) as a function of the duration

application of Eq. (3), the conditional probability histograms for the summer (Fig. 5g) and winter (Fig. 5h) periods and their differences have been evaluated (Fig. 5i).

As previously highlighted, the conditional probabilities of AMAX stress the importance of $\mathrm{WP}_{8,1}$ for any duration, since very low differences (about $2 \%$ ) between the values related to the summer and the winter period have been obtained (Fig. 5i). In particular, the relevance of $\mathrm{WP}_{8,1}$ is more emphasized during the summer period, where the difference between the conditional probabilities under $\mathrm{WP}_{8,1}$ and the other $\mathrm{WP}_{8, \mathrm{x}}$ is much greater than in the case of the winter period. On the other hand, by observing Fig. 5i, it is possible to notice that in the winter period there is an increase of about $8 \%$ in the conditional probability under $\mathrm{WP}_{8,2}$ at all the durations, prevalently due to the higher frequency of occurrence of this WP in the winter period (negative value under $\mathrm{WP}_{8,2}$ in Fig. $5 \mathrm{c}$ ), which depends on a $\mathrm{NAO}+$ pattern. In conclusion, although the $\mathrm{WP}_{8,1}$ causes the greatest part of any duration AMAX during both the summer and winter period (Fig. $5 \mathrm{~g}$ and $\mathrm{h}$, respectively), the contribution of $\mathrm{WP}_{8,2}$ to the occurrence of the AMAX during the winter period (Fig. 5h) increases significantly, as compared to the summer period (Fig. $5 \mathrm{~g}$ ). This happens because $\mathrm{WP}_{8,2}$ has a higher frequency of occurrence in the winter (Fig. 5b) than in the summer period (Fig. 5a), even though the predominance of the AMAX occurred under the $\mathrm{WP}_{8,1}$ also in the winter period is still maintained.

\subsection{Using Reanalysis Indexes for AMAX Classification}

Since the analyses carried out in section 3.4 highlighted the presence of a seasonality in the rainfall AMAX, probably due to different generation mechanisms of precipitation (i.e., stratiform and convective), an attempt to classify rainfall AMAX through two reanalysis indexes is here provided.

Analyses have been carried out for six different rain gauges (i.e., Montalbano Elicona, Palermo Osservatorio Astronomico, Trapani, Sciacca, Enna, and Ragusa - blue circles in Fig. 1) and for the AMAX in between 1979 and 2016, since the ERA-Interim Archive starts on 1979. The number of AMAX collected for the period and the rain gauges considered is equal 

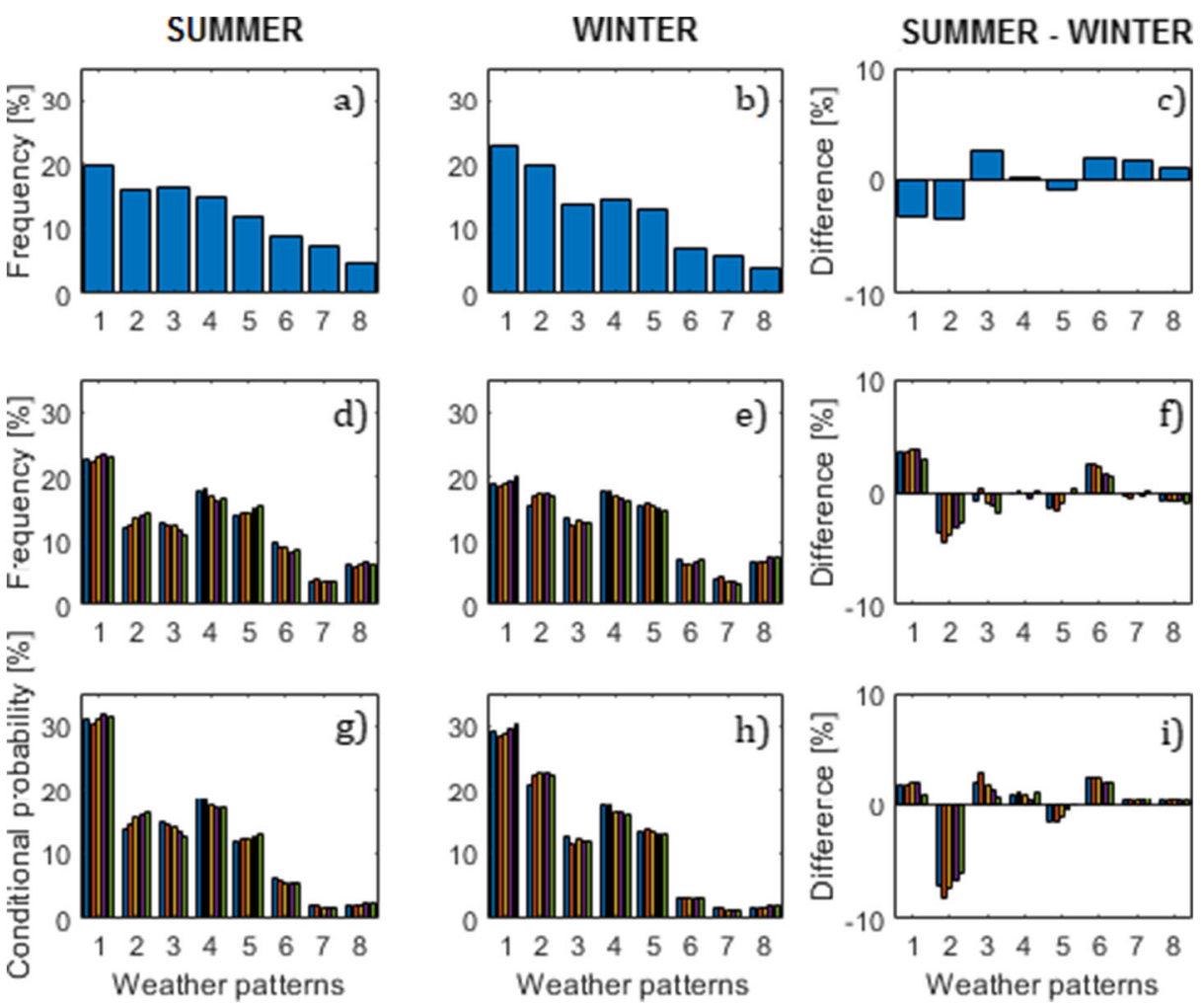

Fig. 5 Frequency histograms of the $\mathrm{WP}_{8, \mathrm{x}}$ occurred during (a) summer and (b) winter period and their differences (c), frequency histograms of the AMAX at all durations occurred in (d) summer and (e) winter period and their differences (f) and conditional probability histogram of the AMAX related to the (g) summer and (h) winter period and their differences (i)

to 33 for Montalbano Elicona, 28 for Palermo Osservatorio Astronomico, 26 for Trapani, 31 for Sciacca, 25 for Enna, and 31 for Ragusa.

Starting from Gabriele and Chiaravalloti (2013), which relate high values of CAPE and low values of DMF to the occurrence of convective and stratiform precipitation, respectively, for each station we considered the maximum value of CAPE and the minimum value of VIDMF at each day. This operation of data selection allowed to create a database of CAPE and VIDMF for each rain gauge from 1979 onwards only for the days with an AMAX.

A first classification of AMAX into convective, stratiform and mixedlunresolved events has been set up through a traditional approach consisting in identifying a fixed threshold for the two reanalysis indexes. In order to find the thresholds of CAPE and VIDMF for the rain gauges considered, we used a subjective criterion that takes into account the similarities among rain gauges, both in terms of spatial location and mean values of daily maximum CAPE and daily minimum VIDMF.

With this regard, it has been noticed that the rain gauges Montalbano Elicona and Enna, which are located in the North-West/Centre of Sicily, present the highest value of mean daily maximum CAPE and mean daily minimum VIDMF for the period 1979-2016. On the opposite, the rain gauges Sciacca and Ragusa, in the south of the region, are those with the lowest values. Finally, the rain gauges Palermo Osservatorio Astronomico and Trapani, 
situated in the North-West of the region, show intermediate values. On the base of these similarities, following Costa et al. (2001) and Gabriele and Chiaravalloti (2013), for each of the previous couples of rain gauge stations, we set the thresholds for CAPE and VIDMF equal to the values of mean daily maximum CAPE and mean daily minimum VIDMF observed between 1979 and 2016 at those stations (Table 1). The values of both the thresholds are consistent with those indicated in Costa et al. (2001) and Gabriele and Chiaravalloti (2013) for the discrimination between convective and stratiform rainfall in Italy.

Once defined the thresholds of CAPE and VIDMF, a joined condition has been used to classify AMAX; in particular, for a given AMAX, if both the CAPE and the VIDMF are higher (lower) than their respective thresholds, then that AMAX is classified as a convective (stratiform) rainfall event, otherwise it is classified as a mixedlunresolved event.

The results of this classification are represented as a polar plot for each duration, where each AMAX is defined through an angle and a radius, representing the Julian day of occurrence and the depth (i.e., amount) of the AMAX, respectively. Following Bayliss and Jones (1993), Burn (1997), and Cunderlik and Ouarda (2009), the Julian day of occurrence of an annual hydrologic event $i$ can be transformed, through a simple linear scaling procedure, to a directional statistic: $\theta_{i}=2 \pi\left(\right.$ Julian day) $/ 365$, where $\theta_{i}$ is the angular value (in radians).

The Fig. 6 shows the polar plots for the rain gauge of Ragusa for all the durations. The same figure shows the percentages of convective, stratiform, and mixedlunresolved events along with the ratio between the percentages of stratiform and convective AMAX as well (lower-right panel). For the sake of brevity, the plots for the remaining rain gauges are reported in Section S.3 of the supplementary material.

The main limitation of such an approach is related to the arbitrary definition of the thresholds for the CAPE and the VIDMF, whose definition impacts in a very important way on the classification.

In order to overcome this drawback, we carried out another classification using a fuzzy logic approach. The fuzzy logic is based on the fuzzy inference, which is a method that interprets the values in the input variable and, based on some set of rules, assigns values to the output variable. The fuzzy logic starts with the concept of a fuzzy set (Zadeh 1965), which is a set without a crisp, clearly defined boundary. A fuzzy set is a combination of elements having a changing degree of membership in the set. Therefore, the membership of the elements to a specific class is measured with a membership function that defines, on the base of a set of rules, the degree of membership (ranging between 0 and 1) of each element to a specific class.

In particular, for each reanalysis index (i.e., CAPE and VIDMF) we defined a couple of membership functions that allow to determine the degree of membership of that index to the convective $\left(d_{\text {conv }}\right)$ or stratiform $\left(d_{\text {strat }}\right)$ class. Figure 7 shows the membership function curves for the CAPE and the VIDMF.

The shape of the membership functions is defined by Eqs. (4) and (5), where the variable $x$ can be both CAPE and VIDMF and the parameters $a$ and $b$ change depending on the reanalysis index considered. In particular, following Costa et al. (2001) and Gabriele and Chiaravalloti

Table 1 CAPE $[\mathrm{J} / \mathrm{kg}]$ and VIDMF $\left[\mathrm{kg} \mathrm{m}^{-2} \mathrm{~s}^{-1}\right]$ thresholds defined through a traditional approach for the six rain gauges considered

\begin{tabular}{llllll}
\hline Sciacca and Ragusa & \multicolumn{2}{c}{ Palermo Osserv. Astron. and Trapani } & \multicolumn{2}{c}{ Montalbano Elicona and Enna } \\
\hline CAPE & 700 & CAPE & 800 & CAPE & 900 \\
VIDMF & $-3.60 \mathrm{E}-04$ & VIDMF & $-3.10 \mathrm{E}-04$ & VIDMF & $-2.50 \mathrm{E}-04$ \\
\hline
\end{tabular}




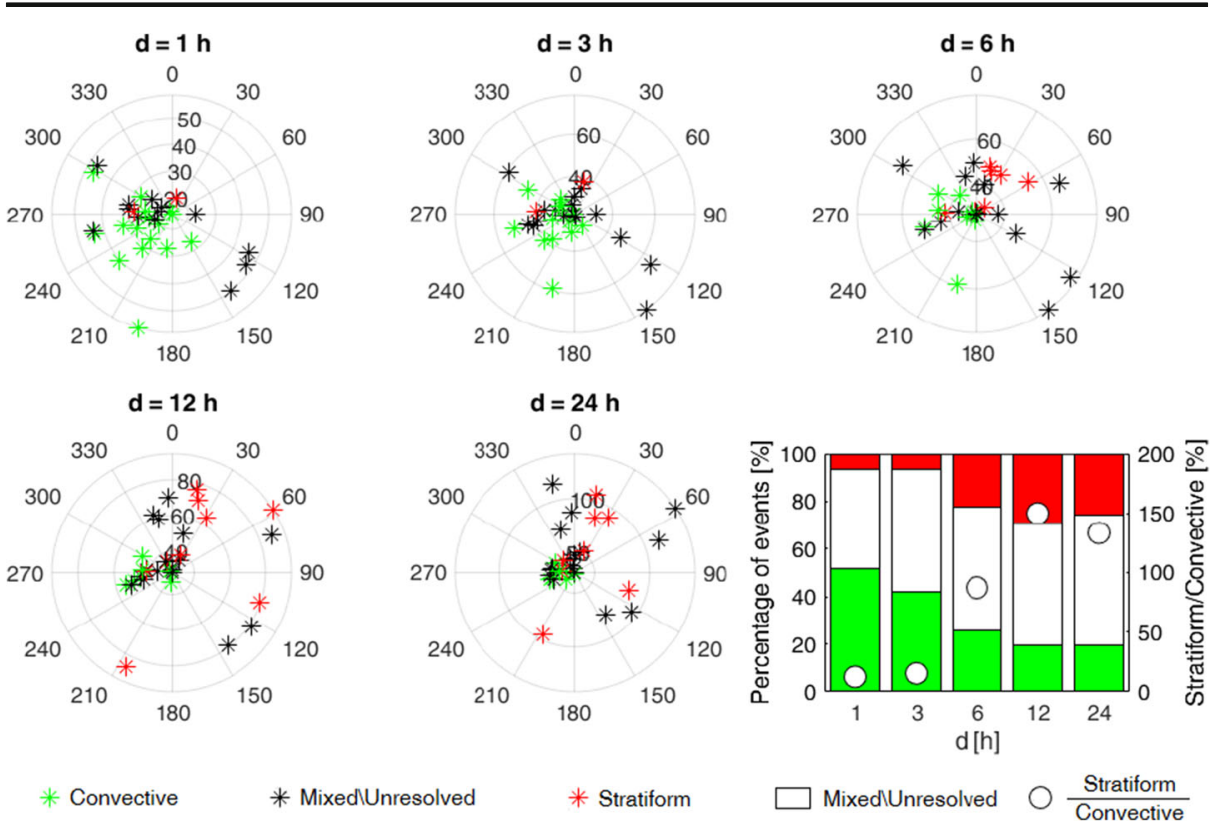

Fig. 6 Polar plots resulted from the traditional approach and representation of the percentage of convective, stratiform and mixedlunresolved AMAX and of the ratio between the percentages of stratiform and convective events (lower-right panel), for the rain gauge Ragusa

(2013), the parameters $a$ and $b$ were set equal to 150 and $1000 \mathrm{~J} / \mathrm{kg}$, respectively, for the CAPE, and equal to $-6.0 \mathrm{E}-04$ and $0 \mathrm{~kg} \mathrm{~m}^{-2} \mathrm{~s}^{-1}$, respectively, for the VIDMF.

$$
\begin{gathered}
d_{\text {conv }}(x, a, b)=\left\{\begin{array}{ccc}
0 & \text { for } & x \leq a \\
2 \cdot\left(\frac{x-a}{b-a}\right)^{2} & \text { for } & a<x \leq \frac{a+b}{2} \\
1-2 \cdot\left(\frac{x-b}{b-a}\right)^{2} & \text { for } & \frac{a+b}{2}<x \leq b \\
1 & \text { for } & x>b
\end{array}\right. \\
d_{\text {strat }}(x, a, b)=\left\{\begin{array}{ccc}
1 & \text { for } & x \leq a \\
1-2 \cdot\left(\frac{x-a}{b-a}\right)^{2} & \text { for } & a<x \leq \frac{a+b}{2} \\
2 \cdot\left(\frac{x-b}{b-a}\right)^{2} & \text { for } & \frac{a+b}{2}<x \leq b \\
0 & \text { for } & x>b
\end{array}\right.
\end{gathered}
$$

The type of the two membership functions (4) and (5), S-shaped in any case, was chosen in order to have a gradual and smooth pattern of the degree of membership under both the two classes of events, which is not achievable with other types of membership functions, such as the trapezoidal or the triangular one.

The two couples of membership functions allow to assess the degree of membership of CAPE and VIDMF values to a class (i.e., convective or stratiform). The membership of a certain event to the convective (or stratiform) class is defined considering the minimum value 

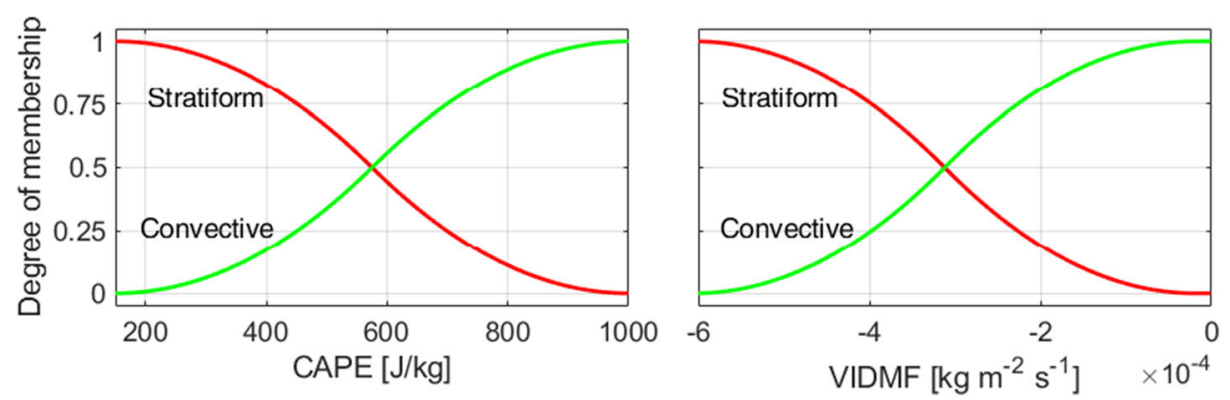

Fig. 7 Membership functions of CAPE (left panel) and VIDMF (right panel) relating to the convective and stratiform classes of events

(i.e., logic AND operator) between the degrees of membership of the related CAPE and VIDMF to that class and comparing it with a cut-off threshold. The logic AND operator has been used to guarantee that both the degrees of membership related to the CAPE and VIDMF, for a given event, are higher than the cut-off threshold, thus falling within the same class (i.e., convective or stratiform). The AMAX not belonging to the convective or stratiform classes are assigned to the mixedlunresolved class. In order to switch from the fuzzy sets, related to the convective and stratiform classes, to a sharper distinction of these two types of events, different cut-off thresholds for the degree of membership have been defined, ranging between 0.1 and 0.9. The choice of the most suitable threshold is not trivial, since it would require the correct identification of the mechanism that generated the AMAX, which is a not available information. Moreover, as already said in the Introduction, the convective and stratiform regimes are not independent or excluded one from another (Houze 1997). From this point of view, the goal is not to identify the pure convective component (or the pure stratiform one) of the AMAX but to identify the mechanism that mainly characterizes AMAX rainfall. For this reason, information available in scientific literature for the Mediterranean area (Feloni et al. 2019; Ruiz-Leo et al. 2013) have been exploited to come out with a value for the cut-off threshold that provides a result consistent with such works. In this perspective, these above-mentioned works presented an algorithm aimed to discriminate between events associated to convective or stratiform mechanisms valid for the two Mediterranean regions of Levante (Spain) and Attica (Greece). The developed algorithm identifies a critical intensity threshold, $\mathrm{R}_{\mathrm{c}}$, which separates convective rainfalls (intensity higher than $R_{c}$ ) from stratiform ones (intensity lower than $R_{c}$ ). Starting from these thresholds, the value of our cut-off threshold has been fixed in order to provide similar percentages of convective and stratiform events to those obtained with the $R_{c}$ approach. In this context, the best result was obtained with a threshold equal to 0.2 .

The Fig. 8 shows the same plots as the Fig. 6 and for the same rain gauge station (i.e., Ragusa) but obtained with the fuzzy approach and a cut-off threshold equal to 0.2. Even in this case, for the sake of brevity, all the other plots have been reported in Section S.4 of the supplementary material.

Comparing Figs. 6 and 8, the first thing worth noting is that the fuzzy logic approach provides always a lower number of events classified as mixed-unresolved. With reference to the lower durations (i.e., 1 and $3 \mathrm{~h}$ ), there is a prevalence of convective over the stratiform and mixedlunresolved AMAX, that is more emphasized in the case of the fuzzy logic approach, which involves a low ratio between stratiform and convective events. Besides, the convective hourly AMAX mostly occur during the summer period (polar plot between $150^{\circ}$ and $330^{\circ}$ ). On the opposite side, at the higher durations (i.e., 12 and $24 \mathrm{~h}$ ) the 


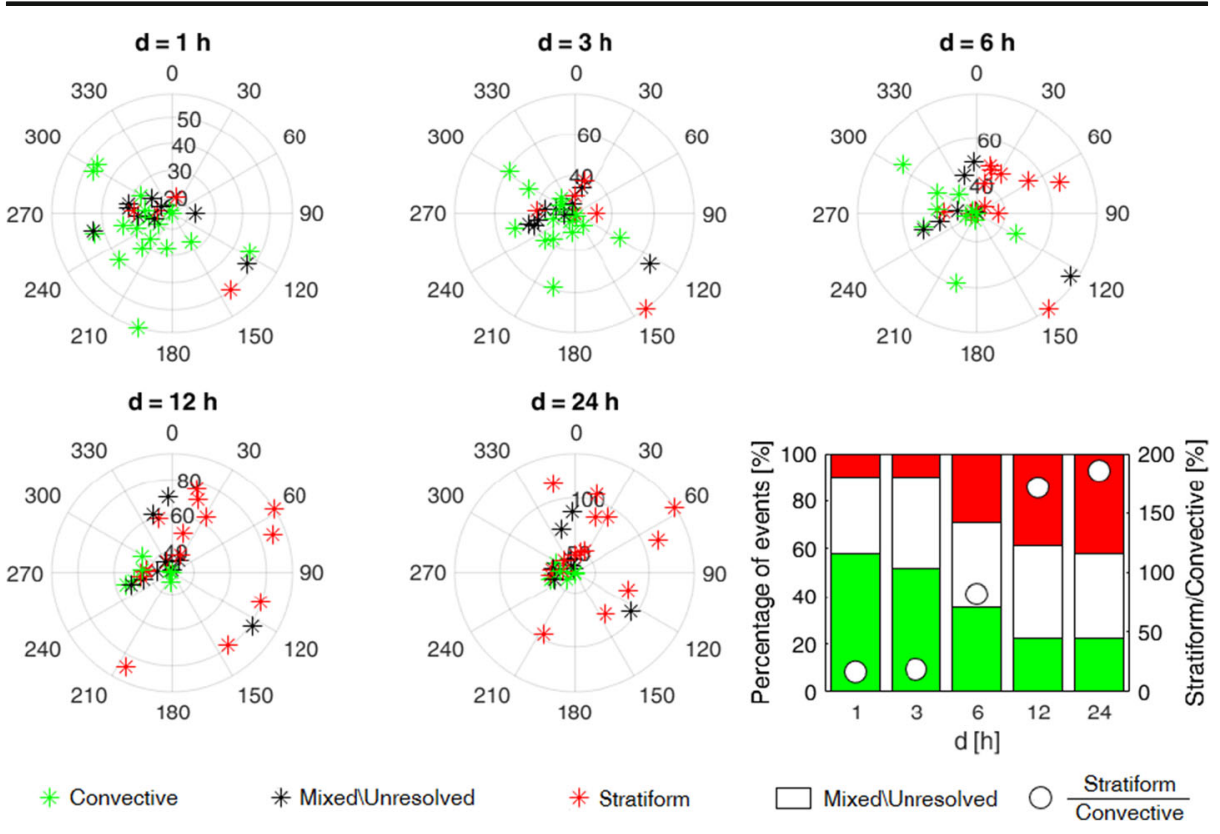

Fig. 8 Polar plots resulted from the fuzzy logic approach $(t=0.2)$ and representation of the percentage of convective, stratiform and mixed lunresolved AMAX and of the ratio between the percentages of stratiform and convective events (lower-right panel), for the rain gauge Ragusa

stratiform AMAX tends to prevail over the convective ones, especially in the case of the fuzzy logic approach, where there are almost the double cases of stratiform over convective events (Fig. 8). At these durations, while in the traditional approach, the mixedlunresolved events prevail over the other two classes of events (Fig. 6), in the fuzzy logic approach they slightly prevail only on the convective AMAX (Fig. 8). Moreover, the stratiform AMAX tend to occur during the winter period, which is the complementary part of the summer period in the polar plot. These results confirm and explain those shown in Fig. 4, where the AMAX occurring during the summer are mainly at the 1-h aggregation, while those occurring during the winter are mainly at the 24-h duration. Similar considerations for the other five gauges are reported in Section S.4 of the supplementary material where the same increasing pattern of the ratio between the occurrence of stratiform and convective AMAX with duration can be observed for the remaining rain gauge stations; in all the cases, this pattern is more evident in the fuzzy logic approach, than the one related to the traditional approach. Such a generalized result confirms that 1) as the duration increases the stratiform component of rainfall becomes more relevant (Feloni et al. 2019) and 2) the seasonality of convective and stratiform AMAX is confirmed, with convective events that tend to occur during the summer period and stratiform AMAX that mainly occur during the winter period, thus confirming the results achieved by Ruiz-Leo et al. (2013).

\section{Conclusions}

A connection between rainfall AMAX and the circulation WPs derived by Neal et al. (2016) for Sicily is here presented. 
The analyses carried out on the whole sample of the pooled AMAX and on the $\mathrm{WP}_{8, \mathrm{x}}$ highlighted the major contribution of $\mathrm{WP}_{8,1}$ to the occurrence of all the pooled AMAX at all durations. This result is confirmed by the Bayesian approach, which recognizes $\mathrm{WP}_{8,1}$ as the one that leads to the occurrence of most of the AMAX for the different durations.

A further analysis made by splitting the year into two periods showed that the percentage of AMAX occurred during the summer period decreases as the duration increases with the highest value reached at the 1-h duration, while the percentage of AMAX occurred in the winter period has an increasing pattern with the duration and reaches the maximum at 24-h duration. In spite of this, for both the summer and winter periods, $\mathrm{WP}_{8,1}$ leads to most of the AMAX at all durations, even though the contribution of $\mathrm{WP}_{8,2}$ to the AMAX occurrence in the winter period becomes relevant as well. In Neal et al. (2016), $\mathrm{WP}_{8,1}$ is classified as a NAO- (negative North Atlantic Oscillation) pattern, in which Sicily is located in correspondence of a negative MSLP. This pattern results in a displacement of air mass from the North Atlantic Ocean to the south of Europe, where Sicily is located, bringing warm and humid air that probably causes high intensity and short duration rainfall events. Furthermore, $\mathrm{WP}_{8,1}$ is the most frequent pattern interesting Europe in the period from 1850 to 2016 and, for this reason, it matches the occurrence of most of the AMAX. As opposite to $\mathrm{WP}_{8,1}, \mathrm{WP}_{8,2}$ is classified as a NAO+ (positive North Atlantic Oscillation) pattern, which leads to cold and dry weather conditions in Sicily because of the humid and wet airflow blowing towards the North-East of Europe.

A criterion to distinguish convective from stratiform and mixedlunresolved components of AMAX, performed through a traditional and a fuzzy logic approach, by using two reanalysis indexes demonstrated a predominance of hourly convective AMAX for all the gauges considered, over the stratiform events, for the summer period, thus reflecting the characteristics of the Mediterranean climate. As the rainfall duration increases, the number of stratiform AMAX events increases, especially in the gauges located in the East of Sicily, even if all the gauges present a high percentage of mixedlunresolved events. Compared to the traditional approach, which led to different threshold values between the six gauges considered, the fuzzy logic is a more flexible approach, since the defined membership functions are valid for all the rain gauges considered. This approach can be extended to the whole island and, if well calibrated, to other areas of the world.

We found that the most severe hourly AMAX are prevalently caused by the $\mathrm{WP}_{8,1}$ during the summer period and the greatest part of them was classified as convective because of their high values of CAPE and VIDMF. This confirms the effects of $\mathrm{WP}_{8,1}$ on the Mediterranean area, namely the transport of warm and humid air, resulting in convective precipitation events, characterized by short duration and high intensity.

In conclusion, if well calibrated for a given area/region, the approach developed could be helpful to forecast the occurrence of severe rainfall events by simply monitoring the atmospheric circulation patterns and the two reanalysis indexes here taken into account.

Acknowledgements Open access funding provided by Università degli Studi di Palermo within the CRUICARE Agreement.

\title{
Compliance with Ethical Standards
}

\author{
Conflict of Interest None.
}


Open Access This article is licensed under a Creative Commons Attribution 4.0 International License, which permits use, sharing, adaptation, distribution and reproduction in any medium or format, as long as you give appropriate credit to the original author(s) and the source, provide a link to the Creative Commons licence, and indicate if changes were made. The images or other third party material in this article are included in the article's Creative Commons licence, unless indicated otherwise in a credit line to the material. If material is not included in the article's Creative Commons licence and your intended use is not permitted by statutory regulation or exceeds the permitted use, you will need to obtain permission directly from the copyright holder. To view a copy of this licence, visit http://creativecommons.org/licenses/by/4.0/.

\section{References}

Arnone E, Pumo D, Viola F, Noto LV, La Loggia G (2013) Rainfall statistics changes in Sicily. Hydrol Earth Syst Sci 17:2449-2458. https://doi.org/10.5194/hess-17-2449-2013

Aronica G, Cannarozzo M, Noto L (2002) Investigating the changes in extreme rainfall series recorded in an urbanised area. Water Sci Technol 45:49-54. https://doi.org/10.2166/wst.2002.0026

Bayliss AC, Jones RC (1993) Peaks-over-threshold flood database: summary statistics and seasonality. Institute of Hydrology (United Kingdom)

Blenkinsop S et al (2018) The INTENSE project: using observations and models to understand the past, present and future of sub-daily rainfall extremes. Adv Sci Res 15:117-126. https://doi.org/10.5194/asr-15-117-2018

Burn D (1997) Catchments similarity for regional flood frequency analysis using seasonality measures. J Hydrol 202:212-230. https://doi.org/10.1016/s0022-1694(97)00068-1

Caracciolo D, Francipane A, Viola F, Noto LV, Deidda R (2018) Performances of GPM satellite precipitation over the two major Mediterranean islands. Atmos Res 213:309-322. https://doi.org/10.1016/j. atmosres.2018.06.010

Collins $\mathrm{M}$ et al (2013) Chapter 12 - long-term climate change: projections, commitments and irreversibility. In: Ipcc (ed) Climate change 2013: the physical science basis. IPCC working group I contribution to AR5. Cambridge University Press, Cambridge

Costa S, Mezzasalma P, Levizzani V, Alberoni PP, Nanni S (2001) Deep convection over Northern Italy: synoptic and thermodynamic analysis. Atmos Res 56:73-88. https://doi.org/10.1016/S0169-8095(00 )00091-0

Cunderlik JM, Ouarda TBMJ (2009) Trends in the timing and magnitude of floods in Canada. J Hydrol 375:471480. https://doi.org/10.1016/j.jhydrol.2009.06.050

Dai A (2011) Drought under global warming: a review. Wiley Interdiscip Rev Clim Chang 2:45-65. https://doi. org/10.1002/wcc.81

Di Piazza A, Conti FL, Noto LV, Viola F, La Loggia G (2011) Comparative analysis of different techniques for spatial interpolation of rainfall data to create a serially complete monthly time series of precipitation for Sicily, Italy. Int J Appl Earth Obs Geoinf 13:396-408. https://doi.org/10.1016/j.jag.2011.01.005

Feloni EG, Baltas EA, Nastos PT, Matsangouras IT (2019) Implementation and evaluation of a convective/ stratiform precipitation scheme in Attica region, Greece. Atmos Res 220:109-119. https://doi.org/10.1016/j. atmosres.2019.01.011

Fereday D, Chadwick R, Knight J, Scaife AA (2017) Atmospheric Dynamics is the Largest Source of Uncertainty in Future Winter European Rainfall. J Clim 31:963-977. https://doi.org/10.1175/jcli-d-170048.1

Field CB et al (2012) IPCC, 2012: managing the risks of extreme events and disasters to advance climate change adaptation. Cambridge University Press, Cambridge

Forestieri A, Caracciolo D, Arnone E, Noto LV (2016) Derivation of rainfall thresholds for flash flood warning in a sicilian basin using a hydrological model. Procedia Engineering 154:818-825. https://doi.org/10.1016/j. proeng.2016.07.413

Gaál L, Molnar P, Szolgay J (2014) Selection of intense rainfall events based on intensity thresholds and lightning data in Switzerland. Hydrol Earth Syst Sci 18:1561-1573. https://doi.org/10.5194/hess-18-15612014

Gabriele S, Chiaravalloti F (2013) Searching regional rainfall homogeneity using atmospheric fields. Adv Water Resour 53:163-174. https://doi.org/10.1016/j.advwatres.2012.11.002

Hegerl GC, Black E, Allan RP, Ingram WJ, Polson D, Trenberth KE, Chadwick RS, Arkin PA, Sarojini BB, Becker A, Dai A, Durack PJ, Easterling D, Fowler HJ, Kendon EJ, Huffman GJ, Liu C, Marsh R, New M, Osborn TJ, Skliris N, Stott PA, Vidale PL, Wijffels SE, Wilcox LJ, Willett KM, Zhang X (2014) Challenges in Quantifying Changes in the Global Water Cycle. Bull Am Meteorol Soc 96:1097-1115. https://doi. org/10.1175/bams-d-13-00212.1 
Houze (1997) Stratiform precipitation in regions of convection: a meteorological paradox? Bull Am Meteorol Soc 78:2179-2196. https://doi.org/10.1175/1520-0477(1997)078<2179:spiroc $>2.0$. co;2

Iturrioz I, Hernández E, Ribera P, Queralt S (2007) Instability and its relation to precipitation over the Eastern Iberian Peninsula. Adv Geosci 10:45-50

Kunkel KE, Pielke RA, Changnon SA (1999) Temporal fluctuations in weather and climate extremes that cause economic and human health impacts: a review. Bull Am Meteorol Soc 80:1077-1098. https://oi. org/10.1175/1520-0477(1999)080<1077:tfiwac>2.0.co;2

Kyselý J, Rulfová Z, Farda A, Hanel M (2016) Convective and stratiform precipitation characteristics in an ensemble of regional climate model simulations. Clim Dyn 46:227-243. https://doi.org/10.1007/s00382015-2580-7

Lang S, Tao W-K, Simpson J, Ferrier B (2003) Modeling of convective-stratiform precipitation processes: sensitivity to partitioning methods. J Appl Meteorol 42:505-527. https://doi.org/10.1175/1520-0450(2003 0042<0505:mocspp $>2.0 . \operatorname{co} ; 2$

Llasat MC, Rigo T, Ceperuelo M, Barrera A (2005) Estimation of convective precipitation: the meteorological radar versus an automatic rain gauge network. Adv Geosci 2:103-109

Mariotti A, Struglia MV, Zeng N, Lau KM (2002) The hydrological cycle in the mediterranean region and implications for the water budget of the Mediterranean Sea. J Clim 15:1674-1690. https://doi.org/10.1175 /1520-0442(2002)015<1674:thcitm>2.0.co;2

Moncrieff MW, Green JSA (1972) The propagation and transfer properties of steady convective overturning in shear. Q J R Meteorol Soc 98:336-352. https://doi.org/10.1002/qj.49709841607

Moncrieff MW, Miller MJ (1976) The dynamics and simulation of tropical cumulonimbus and squall lines. Q J R Meteorol Soc 102:373-394. https://doi.org/10.1002/qj.49710243208

Neal R, Fereday D, Crocker R, Comer RE (2016) A flexible approach to defining weather patterns and their application in weather forecasting over Europe. Meteorol Appl 23:389-400. https://doi.org/10.1002 /met.1563

Noto LV, La Loggia G (2009) Use of L-moments approach for regional flood frequency analysis in Sicily, Italy. Water Resour Manag 23:2207-2229. https://doi.org/10.1007/s11269-008-9378-X

Rasmusson EM (1971) A study of the hydrology of Eastern North America using atmospheric vapor flux data. Mon Weather Rev 99:119-135. https://doi.org/10.1175/1520-0493(1971)099<0119:asotho >2.3.co;2

Richardson D, Fowler HJ, Kilsby CG, Neal R (2018) A new precipitation and drought climatology based on weather patterns. Int J Climatol 38:630-648. https://doi.org/10.1002/joc.5199

Ruiz-Leo AM, Hernández E, Queralt S, Maqueda G (2013) Convective and stratiform precipitation trends in the Spanish Mediterranean coast. Atmos Res 119:46-55. https://doi.org/10.1016/j.atmosres.2011.07.019

Rulfova Z, Kyselý J (2013) Disaggregating convective and stratiform precipitation from station weather data. Atmos Res 134:100-115. https://doi.org/10.1016/j.atmosres.2013.07.015

Tremblay A (2005) The Stratiform and Convective Components of Surface Precipitation. J Atmos Sci 62:15131528. https://doi.org/10.1175/jas3411.1

Zadeh LA (1965) Fuzzy sets. Inf Control 8:338-353. https://doi.org/10.1016/S0019-9958(65)90241-X

Publisher's Note Springer Nature remains neutral with regard to jurisdictional claims in published maps and institutional affiliations. 